\title{
EURODYN 2020
}

XI International Conference on Structural Dynamics

\section{PROCEEDINGS}

\section{Volume I}

M. Papadrakakis, M. Fragiadakis, C. Papadimitriou (Eds.) 



\section{EURODYN 2020}

Proceedings of the XI International Conference on Structural Dynamics Streamed from Athens, Greece

23-26 November 2020

Edited by:

M. Papadrakakis

National Technical University of Athens, Greece

\section{Fragiadakis}

National Technical University of Athens, Greece

\section{Papadimitriou}

University of Thessaly, Greece

\section{A publication of:}

Institute of Structural Analysis and Antiseismic Research School of Civil Engineering

National Technical University of Athens (NTUA)

Greece 


\section{EURODYN 2020}

XI International Conference on Structural Dynamics

M. Papadrakakis, M. Fragiadakis, C. Papadimitriou (Eds.)

First Edition, September 2020

(c) The authors

ISBN (set): 978-618-85072-2-7

ISBN (vol I): 978-618-85072-0-3 


\title{
RAIL-BRIDGE INTERACTION EFFECTS IN SINGLE-TRACK MULTI- SPAN BRIDGES. EXPERIMENTAL RESULTS VERSUS NUMERICAL PREDICTIONS UNDER OPERATING CONDITIONS
}

\author{
M.D. Martínez-Rodrigo ${ }^{1}$, P. Galvín ${ }^{2}$, E. Moliner $^{1}$ and A. Romero ${ }^{2}$ \\ ${ }^{1}$ Universitat Jaume I, Mechanical Engineering and Construction Department \\ Avda. Sos Baynat s/n, 12071 Castellón, Spain \\ e-mail: \{mrodrigo, molinere\}@uji.es \\ ${ }^{2}$ Universidad de Sevilla, Escuela Técnica Superior de Ingeniería \\ Camino de los Descubrimientos s/n, 41092 Sevilla, Spain \\ \{pedrogalvin,aro\}@us.es
}

Keywords: Railway bridges, rail-bridge interaction, experimental measurements

\begin{abstract}
This paper is devoted to the analysis of rail-bridge interaction effects in railway bridges under the circulation of moving trains. In a first approach, a bidimensional Finite Element model is implemented. The rail and the bridge are represented as Bernouilli-Euler beams, and a three-layer discrete track model accounting for the damping and flexibility of rail pads, ballast and subgrade is considered. In the model, several elastically supported spans are included, coupled by the presence of the track. First a sensitivity analysis is performed on the track parameters. A numerical receptance test is simulated on the rails showing that the track damping parameters influence the response only in the vicinity of the track natural frequencies, which are much higher than the bridge's. Then, the maximum acceleration of the bridge is evaluated under equidistant trains and consistent conclusions are extracted regarding the track parameters. Last, the number of spans included in the model is evaluated showing that limiting the model to one span does not necessarily lead to the highest response in terms of the bridge acceleration. Finally, the response of an existing two-span single-track bridge belonging to a conventional Spanish line is evaluated under the circulation of the Altaria Talgo train. Numerical predictions are compared to experimental results obtained in a recent campaign. The prediction of the vertical acceleration at the sensors located along the longitudinal symmetry axis is adequate. From the experimental results the coupling effect between the adjacent decks in each span is evident suggesting the need of analyzing this phenomenon with more sophisticated models.
\end{abstract}




\section{INTRODUCTION}

Railway induced vibrations are a matter of concern for engineers and authorities in recent societies. In many countries, nowadays High-Speed services allow intense mobility between distant highly populated urban areas. The crescent density of traffic and the train operational speeds require, nonetheless, an outstanding response of railway infrastructures in order to ensure traffic safety, passenger comfort and adequate environmental conditions in the surrounding areas.

Comprising an important proportion of the railway infrastructure, railway bridges have received considerable attention in the last years and, to ensure traffic safety and passenger comfort, their design must accomplish strict requirements [1]. In particular, short-to-medium span simply-supported (SS) bridges with ballasted tracks are prone to experience high deck vertical accelerations which may lead to ballast deconsolidation, rail misalignment and other related problems [2]-[11]. In this context, a deep understanding of train-track-bridge interaction mechanisms is essential in order to be able to predict and assess the dynamic response of such structures. A state-of-the-art review on the evolution of numerical models and experimental tests focusing on validation, safety assessment and long-term performance investigation of traintrack-bridge systems was recently presented by Zhai et al. [5].

Railway axle loads and bridges interact through the track infrastructure. The track distributes the axle loads and may exert a restraining effect on the bridges' boundary conditions [6] and a coupling effect among consecutive spans of the same viaduct [7], or between adjacent singletrack decks [8]. Nevertheless, in many publications these effects are disregarded and the influence of the super-structure composed by the rails, sleepers and ballast, in ballasted tracks, is still not well known.

In this contribution, the dynamic behavior of multi-span single-track bridges is investigated with the aim of evaluating the effect of the continuity of the track on the bridge vertical response. In section 2 an existing bridge object of study is described, along with the numerical model. In section 3, the results of a preliminary sensitivity analysis on a few track parameters is presented. In section 4, the results of an experimental campaign recently performed on the bridge are compared with numerical predictions. Finally, some conclusions are extracted regarding the effect of the track super-structure on the bridge acceleration response.

\section{BRIDGE DESCRIPTION AND NUMERICAL MODEL}

\subsection{Bridge description}

The bridge under study is a bridge crossing the Old Guadiana River in the conventional railway line Madrid-Alcázar de San Juan-Jaén in the Alcázar de San Juan-Manzanares section (see Fig. 1). It is a double track concrete bridge composed by two identical SS bays. In each span, the horizontal structure is formed by two structurally independent decks, one for each track. Each deck is composed by a concrete slab resting on five pre-stressed concrete rectangular girders with no transverse stiffening elements (see Fig. 2). The longitudinal girders rest on the two abutments and on a central support through neoprene bearings. Each deck accommodates a ballasted track with Iberian gauge UIC60 rails and mono-block concrete sleepers with a spacing of $0.60 \mathrm{~m}$.

\subsection{Numerical model}

In a first approach, the numerical model described in what follows is used. Only one singletrack deck is represented in both bays as two successive Bernoulli-Euler (B-E) beams resting on elastic supports, accounting for the neoprene bearings elastic vertical stiffness. The two rails 
are treated as an equivalent single B-E beam as well. A three layer discrete track model (see Fig. 3) as the one proposed by Zhai [9] is implemented, where the damping and stiffness of rail pads, ballast and subgrade are included at the sleepers positions.
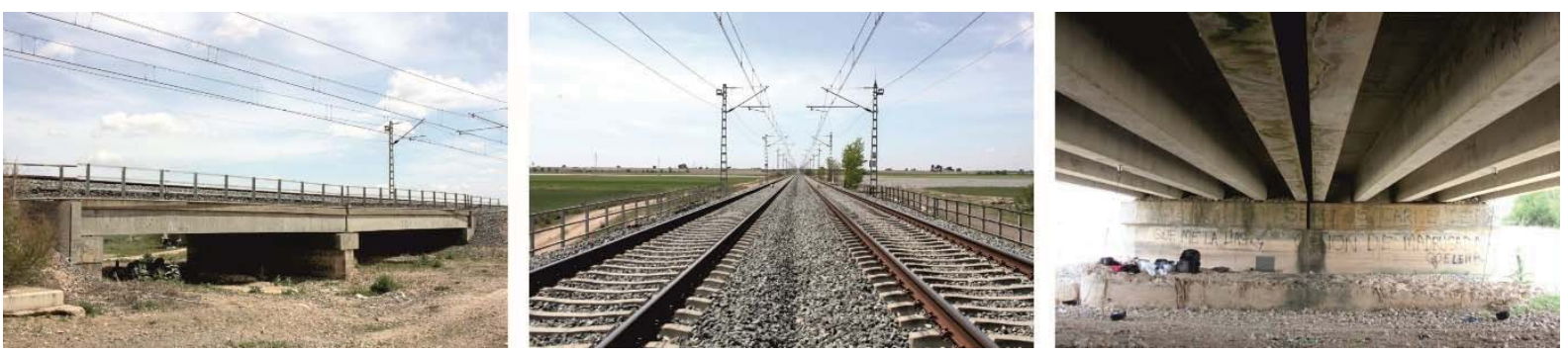

Figure 1: Old Guadiana Bridge photographs.

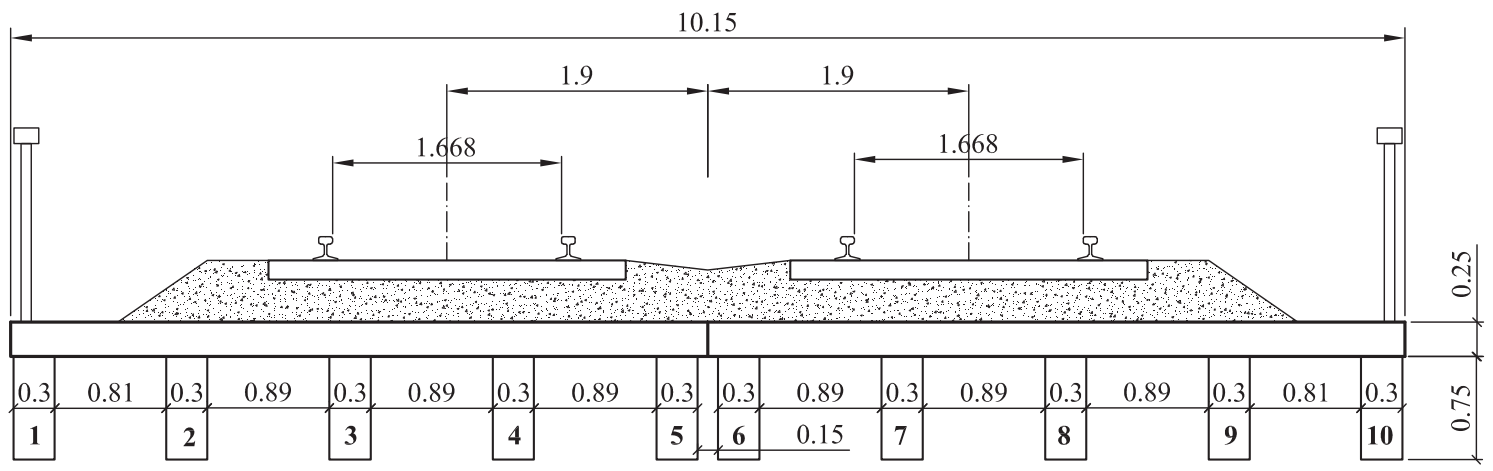

Figure 2: Old Guadiana Bridge cross-section.

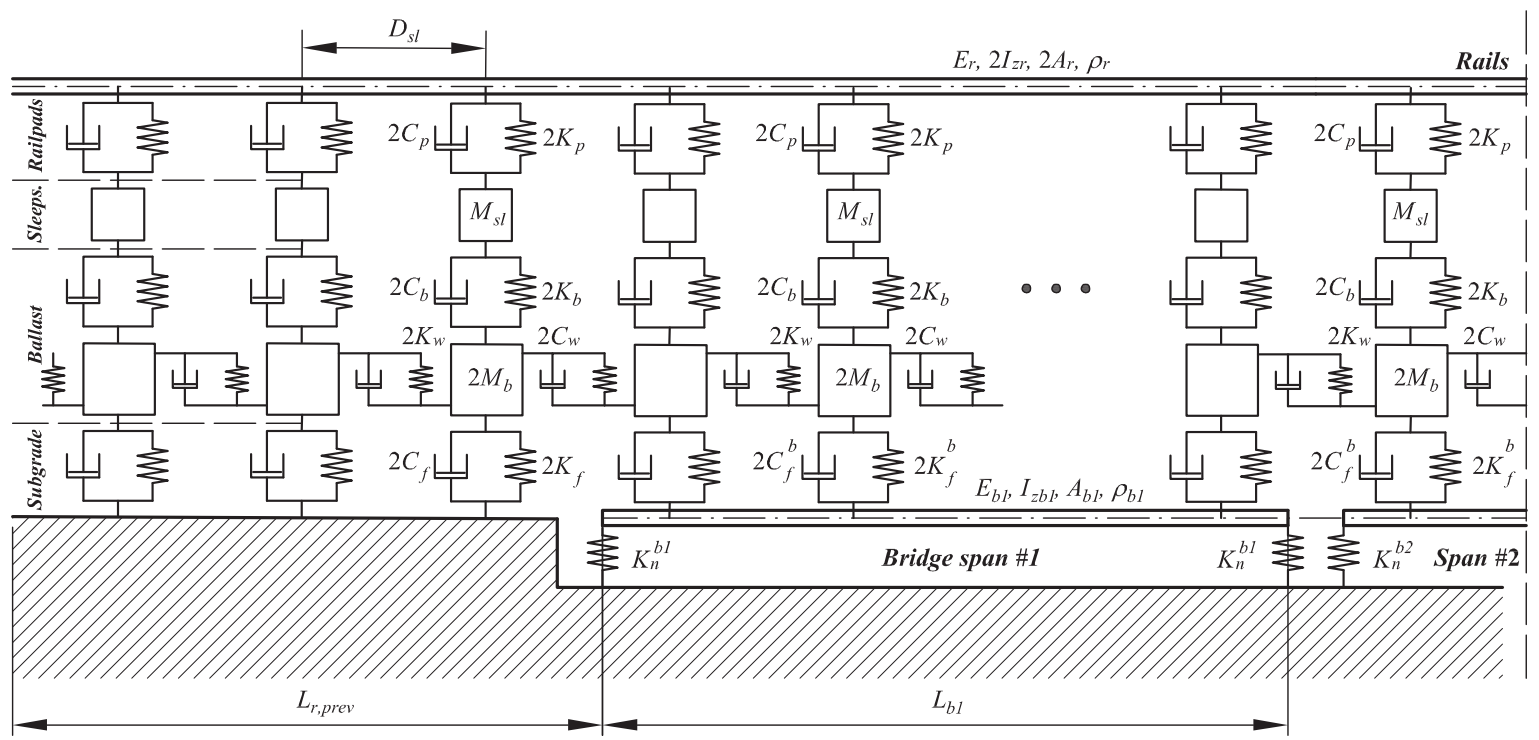

Figure 3: Numerical track-bridge interaction model.

In order to simulate the axle vertical forces, a constant moving load model is selected, therefore neglecting vehicle-structure interaction effects. The model, as described above, is generated using Finite Elements in Ansys software. Then, the equations of motion of the complete system are integrated in the time domain applying Newmark-Betta constant acceleration algorithm programmed in Matlab. 


\subsection{Parameter selection and model updating}

In the last years, different authors have proposed discrete track models for the analysis of railway induced vibrations. Fig. 4 shows the evident dispersity in the values of four parameters admitted in previous publications: the rail pads and ballast vertical stiffness and damping $K_{p}$, $C_{p}, K_{b}$ and $C_{b}$. First, a set of nominal or reference values for all the track parameters is selected on the basis of the literature review. Then, the bridge parameters, assumed identical in both bays, (Modulus of Elasticity $E_{b i}$, moment of inertia $I_{z b i}$ and linear mass $m_{b i}$ ) are adjusted in order to reproduce static and dynamic tests performed on the structure right before its opening [23]. In Table 1 the bridge and track reference parameters are included. These will be the ones used in the experimental validation (section 4). The fundamental frequency of the track-bridge system for these parameters equals $10.07 \mathrm{~Hz}$. A damping ratio of $1.565 \%$ is assigned to any mode as per [24] for pre-stressed concrete bridges of the particular span length.
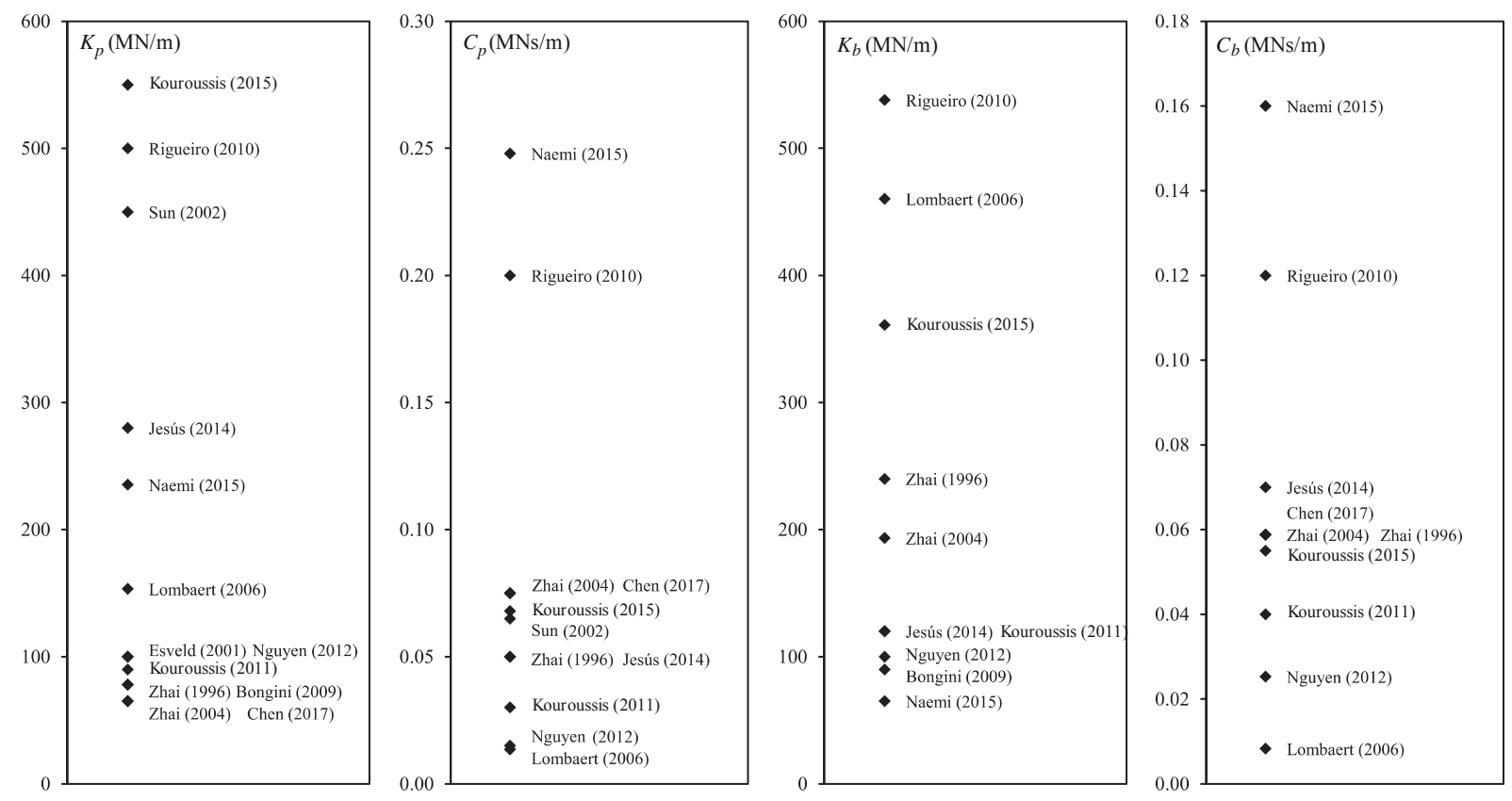

Figure 4: Rail pad and ballast layer stiffness and damping values admitted by different authors in the past for comparable ballast layers thicknesses and sleepers distances [6],[9]-[20].

\begin{tabular}{cc|cc}
\hline \multicolumn{2}{c|}{ Rail and bridge parameters } & \multicolumn{2}{c}{ Track parameters per rail seat } \\
\hline$A_{r}\left(\mathrm{~m}^{2}\right)$ & $76.86 \mathrm{E}-4$ & $K_{p}(\mathrm{~N} / \mathrm{m})$ & $1 \mathrm{E} 8$ \\
$\mathrm{E}_{\mathrm{r}}(\mathrm{Pa})$ & $2.1 \mathrm{E} 11$ & $C_{p}(\mathrm{Ns} / \mathrm{m})$ & $7.5 \mathrm{E} 4$ \\
$I_{z r}\left(\mathrm{~m}^{4}\right)$ & $3055 \mathrm{E}-8$ & $M_{s l}(\mathrm{~kg})$ & 300 \\
$\rho_{r}\left(\mathrm{~m}^{3}\right)$ & 7850 & $K_{b}(\mathrm{~N} / \mathrm{m})$ & $1.933 \mathrm{E} 8$ \\
$\mathrm{D}_{s l}(\mathrm{~m})$ & 0.60 & $C_{b}(\mathrm{Ns} / \mathrm{m})$ & $5.88 \mathrm{E} 4$ \\
\cline { 1 - 1 }$L_{b i}(\mathrm{~m}), N_{s p}$ & $11.93,2 \mathrm{spans}$ & $M_{b}(\mathrm{~kg})$ & 317.91 \\
$\left(I_{z} \cdot E\right)_{b i}\left(\mathrm{Nm}^{2}\right)$ & $7.09 \mathrm{E} 9$ & $K_{f}(\mathrm{~N} / \mathrm{m})$ & $7.3987 \mathrm{E} 7$ \\
$m_{b i}\left(\mathrm{~kg} / \mathrm{m}^{2}\right)$ & 8727 & $C_{f}(\mathrm{Ns} / \mathrm{m})$ & $3.115 \mathrm{E} 4$ \\
$\zeta_{b i}(\%)$ & 1.565 & $K_{w}(\mathrm{~N} / \mathrm{m})$ & $7.84 \mathrm{E} 7$ \\
$K_{n, b i}(\mathrm{~N} / \mathrm{m})_{\text {st } / \mathrm{dyn}}$ & $11.165 \mathrm{E} 8 / 22.33 \mathrm{E} 8$ & $C_{w}(\mathrm{Ns} / \mathrm{m})$ & $8 \mathrm{E} 4$ \\
\hline
\end{tabular}

Table 1: Bridge-track reference parameters 
As per the subgrade stiffness and damping coefficients inside the bridge, $100 K_{f}$ and $0 \mathrm{Ns} / \mathrm{m}$ have been assigned as it is assumed that the ballast layer rests directly on the concrete slab.

A track length of $20 \mathrm{~m}$ is included before and after the two-span bridge, equivalent to more than 30 times the sleeper distance, which is considered adequate attending to previous publications [21], [22]. A convergence analysis is performed on this length ensuring the adequacy of this value.

\section{SENSITIVITY ANALYSIS}

\subsection{Track receptance}

Fist, the track dynamic response is evaluated numerically. To this end a harmonic test is performed on approximately $50 \mathrm{~m}$ of track (in the absence of bridge). A vertical harmonic load of $210 \mathrm{kN}$ is applied at the central section of the double rail and the vertical displacement amplitude is determined in the same location. The forcing frequency varies between 1 and 2000 $\mathrm{Hz}$ in increments of $0.5 \mathrm{~Hz}$. Fig. 5 shows the results for individual variations of $C_{p}, C_{b}, C_{f}$ and $C_{w}$ with respect to the reference values included in Table 1.

Two resonance frequencies are clearly detected in the proximities of 170 and $1350 \mathrm{~Hz}$. The variations in the damping parameters affect the response only close to resonance. As the maximum frequency of interest in the bridge acceleration response is $60 \mathrm{~Hz}$, the effect of these parameters on the bridge response should be very small. In the following section this particular issue is checked.
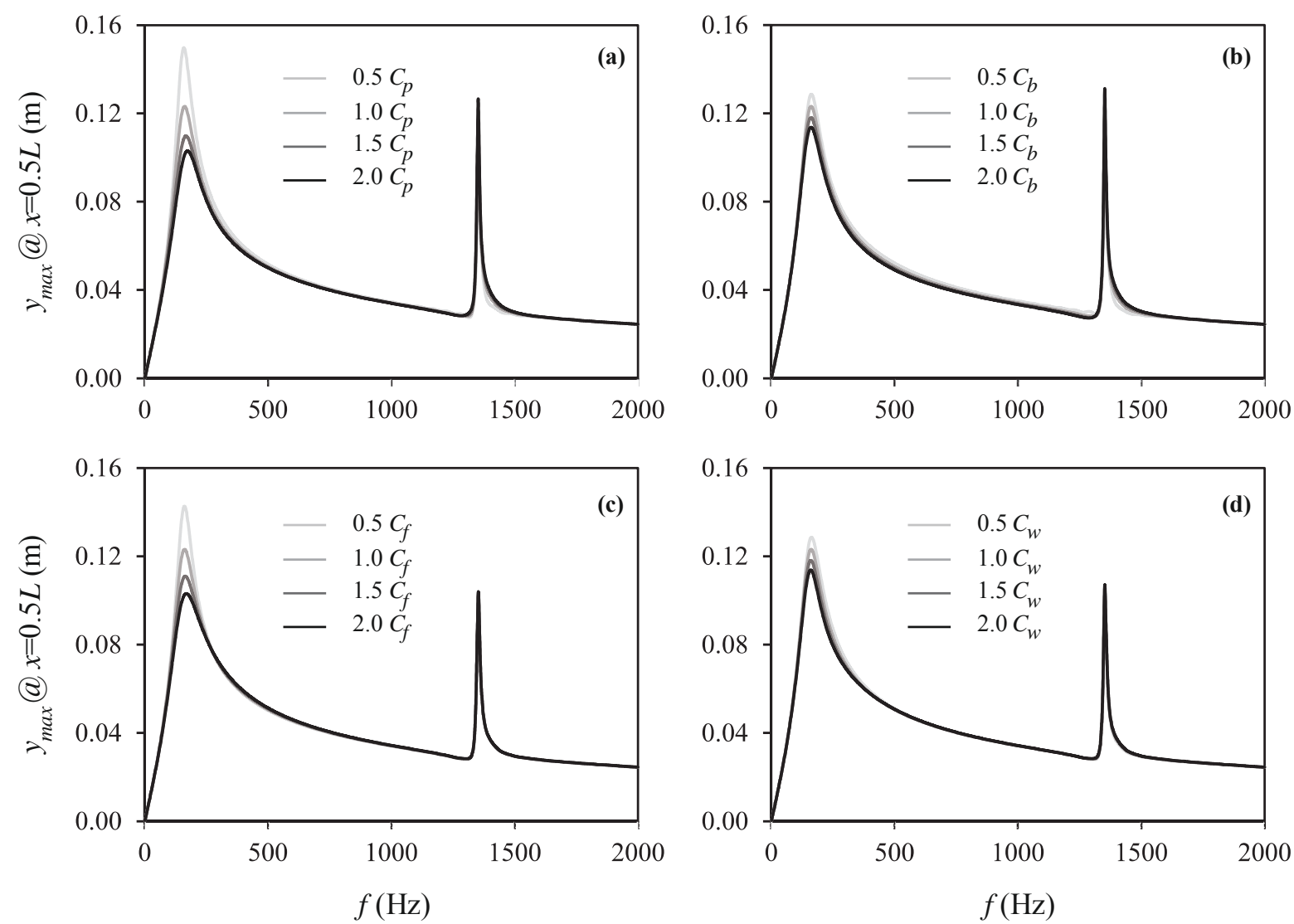

Figure 5: Receptance numerical test performed on the track model for independent variations of $C_{p}, C_{b}, C_{f}$ and $C_{w}$. 


\subsection{Bridge maximum acceleration under train of equidistant loads}

Second, the effect of the variations on four track parameters: the stiffness and damping coefficients of the rail pads, $K_{p}$ and $C_{p}$, and of the ballast, $K_{b}$ and $C_{b}$ on the bridge maximum acceleration response is investigated. To this end, the response of the bridge is obtained under the circulation of an artificial train of 20 equidistant loads of $210 \mathrm{kN}$ separated $18 \mathrm{~m}$, with the aim of inducing two clear resonances on the structure. The bridge time-history response in terms of displacements and accelerations is obtained for 60 velocities of circulation in the range $[40,100] \mathrm{m} / \mathrm{s}$. A Chebyshev order 3 filter is applied to the acceleration response filtering contributions below $1 \mathrm{~Hz}$ and above $60 \mathrm{~Hz}$. After filtering, maximum response envelopes are obtained for values of the track parameters:

$$
[0.5,1,2,4] \cdot K_{p} \quad[0,0.5,1,2] \cdot C_{p} \quad[0.5,1,2,4] \cdot K_{b} \quad[0,0.5,1,2] \cdot C_{b}
$$

where the values of $K_{p}, C_{p}, K_{b}$ and $C_{b}$ are those in Table 1. Fig. 6 shows the evolution of the maximum acceleration, which always takes place in the center of the second span, in absolute value in terms of the velocity for individual variations of each track parameter.
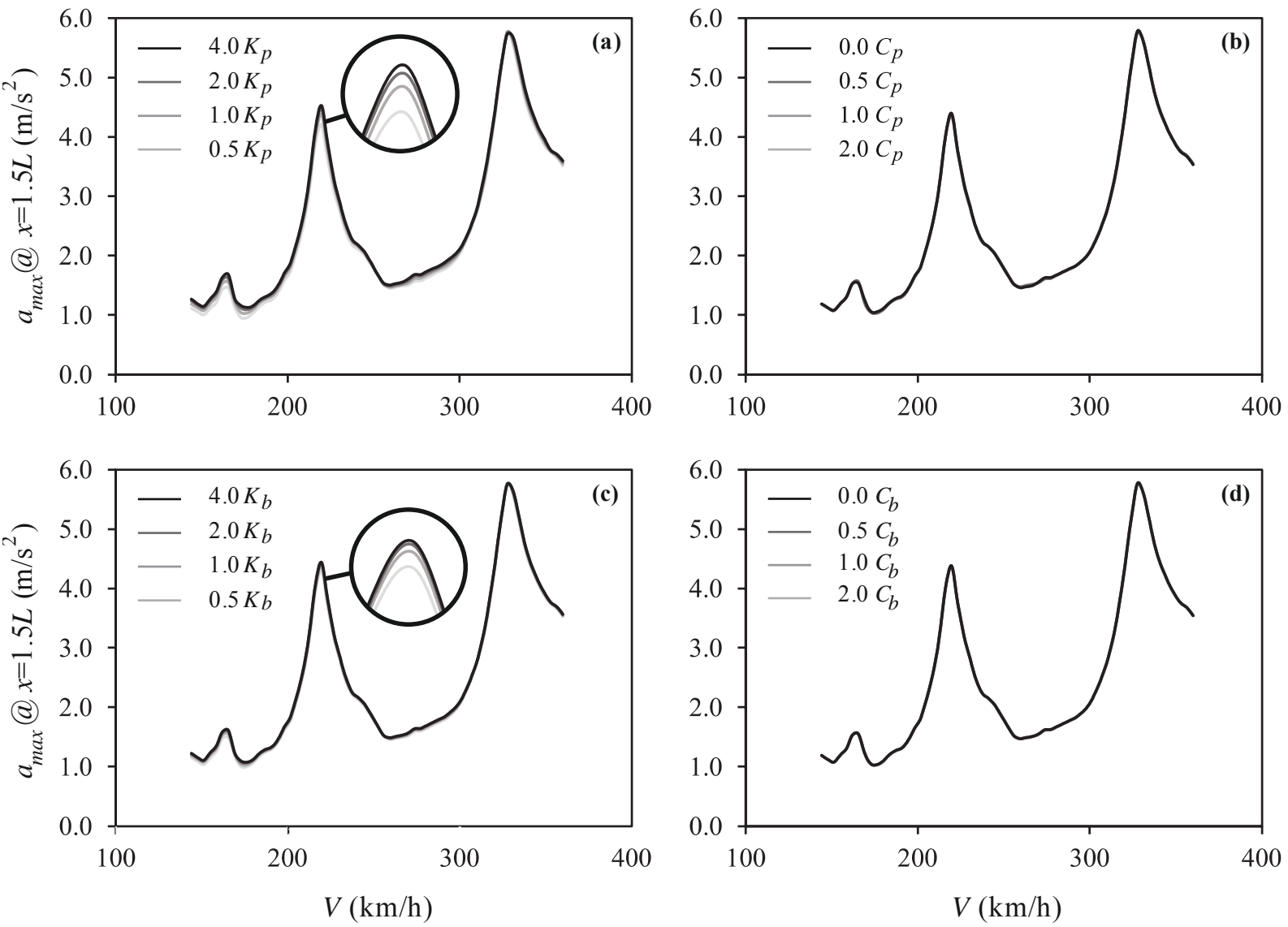

Figure 6: Maximum acceleration vs. velocity for individual variations of $K_{p}, K_{b}, C_{p}$, and $C_{b}$.

In all the plots shown in Fig. 6 three resonant peaks can be detected, corresponding to second, third and fourth resonances of the fundamental mode of the bridge, which in the reference case presents a frequency $f_{1}=10.07 \mathrm{~Hz}$. These theoretical resonant speeds can be calculated as:

$$
\mathrm{V}_{1}^{\mathrm{r}, \mathrm{j}=2}=\frac{\mathrm{df}_{1}}{2} 3.6=326.27 \frac{\mathrm{km}}{\mathrm{h}} \mathrm{V}_{1}^{\mathrm{r}, \mathrm{j}=3}=217.5 \frac{\mathrm{km}}{\mathrm{h}} \mathrm{V}_{1}^{\mathrm{r}, \mathrm{j}=4}=163.1 \frac{\mathrm{km}}{\mathrm{h}}
$$

The individual variations considered in the track do not affect significantly the reference fundamental frequency. From the observation of Fig. 6 (c)-(d) it may be concluded that the 
influence of the variations in the rail pads and ballast damping constants is negligible on the maximum acceleration response of the bridge for the reference values of the remaining parameters, as expected from the results of the receptance study. The parameter that seems to affect the most the acceleration envelope at the most critical section is the rail pad stiffness $K_{p}$, leading to a decrease in the maximum acceleration at resonance as $K_{p}$ reduces (for more flexible rail pads). This effect is more visible for higher resonance orders. The same tendencies, although in a less pronounced manner, are observed in terms of the variations considered in the ballast stiffness $K_{b}$.

\subsection{Influence of the number of spans}

Last in the sensitivity analysis, the effect of including a different number of spans in the numerical model on the maximum bridge response is investigated. Due to the longitudinal coupling exerted by the track on the structurally independent decks, the maximum response could differ depending on the number of spans. The analysis is performed in two cases: including and neglecting the decks neoprene bearings. In Fig. 7 the maximum acceleration at mid-span is represented for the same train of equidistant loads used in the previous subsection. All the bridge and track parameters adopt the reference values. Fig. 7(a) corresponds to the simplysupported (SS) case, i.e. no neoprene bearings, while Fig. 7(b) represents the elastically supported case, i.e. considering the neoprene bearings vertical flexibility. Colors red, black and grey are selected to represent results computed with one, two and three spans, respectively. Then, solid, dashed and dotted lines correspond to the response at mid-span of the first, second and third spans, respectively.
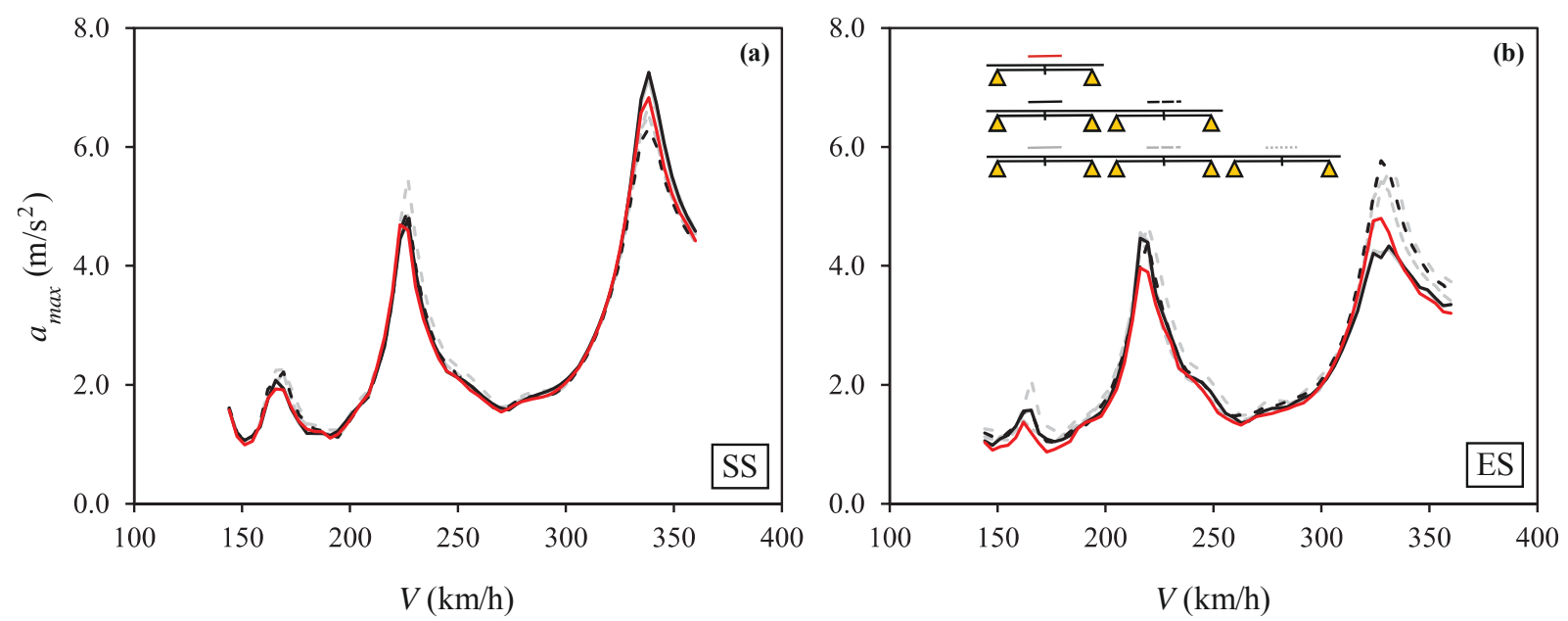

Figure 7: Maximum acceleration vs. velocity for models with one, two and three spans. (a) Simply-supported and (b) elastically-supported decks.

From the analysis of Fig. 7 one may conclude that: (i) the model leading to the maximum predicted acceleration and the most critical section depend on the maximum velocity considered; (ii) the difference between the three models is more relevant at resonance; (iii) in the particular case under study considering just one span does not predict the maximum response at any resonant peak. From the previously said, if the rail is included in the model and computational time is not an issue, including all the spans in the model may be on the safety side when it comes to predicting the maximum vertical acceleration response. 


\section{EXPERIMENTAL VALIDATION}

\subsection{Description of experimental campaign}

In May 2019 the authors performed an experimental campaign on Old Guadiana Bridge with the purpose of characterizing the structure and soil dynamic properties along with the bridge dynamic response under railway traffic (see Fig. 8). As per the acquisition equipment, a portable acquisition system LAN-XI of Brüel \& Kjaer was used. The acquisition system fed the sensors (accelerometers) and an instrumented impact hammer in the case of the soil tests. It also performed the Analog/Digital conversion (A/D). The A/D was carried out at a high sampling frequency that avoided aliasing effects using a low-pass filter with a constant cut-off frequency. The sampling frequency was $f_{s}=4096 \mathrm{~Hz}$. The acquisition equipment was connected to a laptop for data storage. Endevco model 86 piezoelectric accelerometers were used with a nominal sensitivity of $10 \mathrm{~V} / \mathrm{g}$ and a lower frequency limit of approximately $0.1 \mathrm{~Hz}$. The acquisition system was configured to avoid the sensors' overload.
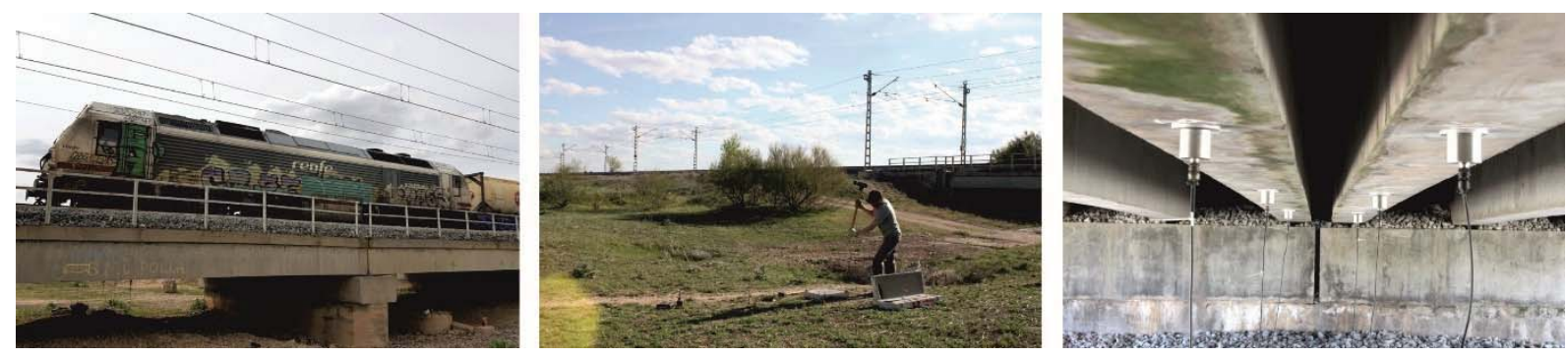

Figure 8: Experimental campaign photographs.

From the dynamic characterization of the soil, which was carried out by the by Spectral Analysis of Surface Waves test a rather stiff soil was identified with a shear wave velocity higher than $250 \mathrm{~m} / \mathrm{s}$ in the upper soil layer. The bridge response depends on soil-structure interaction (SSI) and soil stratigraphy. However, due to the high soil stiffness identified, in a first approach these effects are disregarded.

As per the bridge structure, eighteen accelerometers were connected to the lower horizontal surface of the decks longitudinal girders in the locations indicated in Fig. 9.

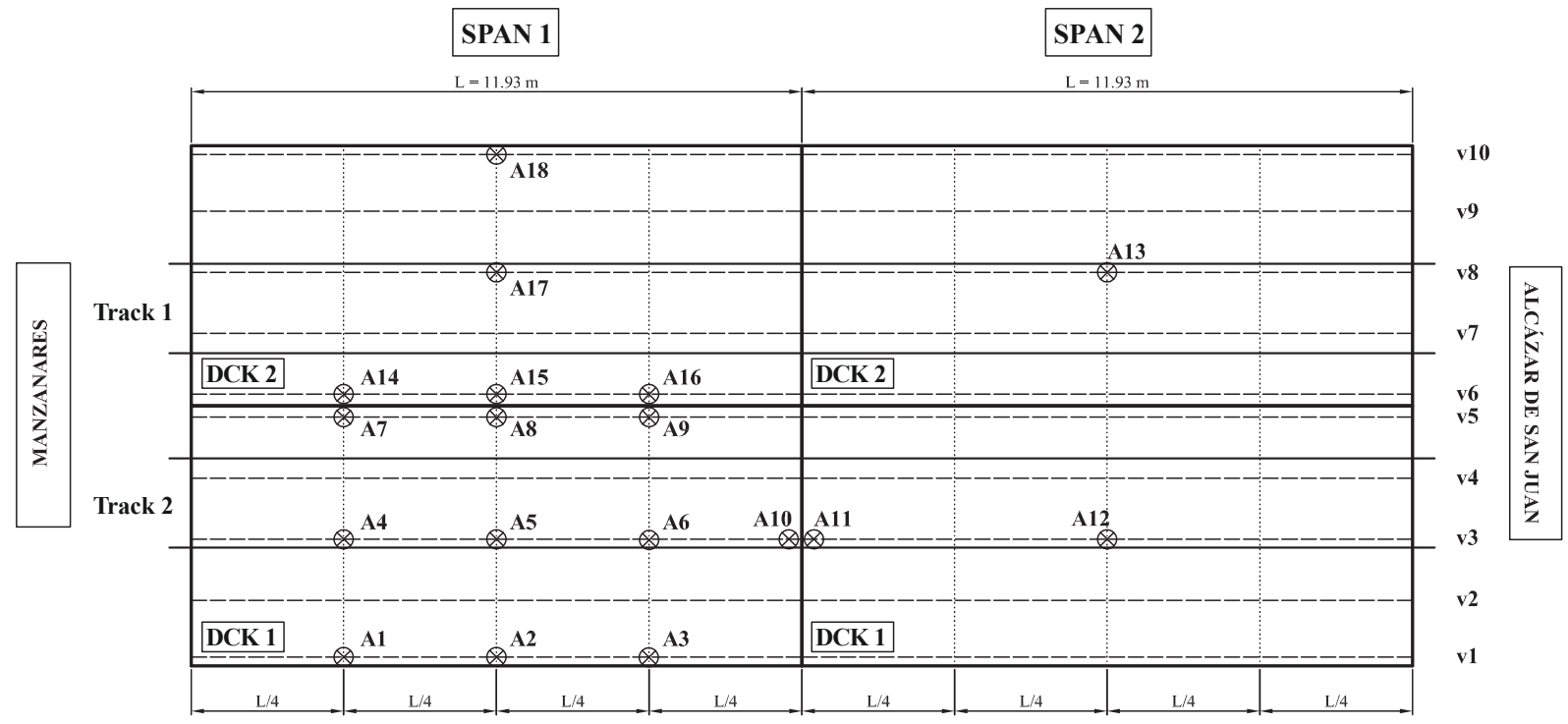

Figure 9: Sensors placement in experimental campaign. 


\subsection{Numerical predictions vs. experimental measurements}

During the campaign the response of the structure was recorded under the circulation of different trains. Two of these circulations are included in this section. Both correspond to the medium distance Renfe Altaria Talgo VI train travelling along tracks 2 and 1 (see Fig. 9) in the directions South-North (Manzanares-Alcázar de San Juan) and North-South, respectively. Fig. 10 and Fig. 11 show photographs of the trains and a scheme of the axles distances. Also, Table 2 includes the train axles arrangement and loads.

First, the speeds were identified from the frequency associated to the bogie distance leading to approximately $155 \mathrm{~km} / \mathrm{h}$ in both cases. Then, the response of the bridge was calculated using the numerical model described in section 2.2 with the properties included in Table 1, with the exception of structural damping which was assumed as $3.1 \%$ for the fundamental frequency, $10.065 \mathrm{~Hz}$, and $1.56 \%$ for $90 \mathrm{~Hz}$ (Eurocode value). The first value was identified during the proof load test. The numerical response, integrated in the time domain using the full FE model, is also filtered between 1 and $30 \mathrm{~Hz}$, applying the same procedure as with the experimental records. Given the bidimensional nature of the numerical model, only the response at sensors installed underneath beams 3 and 8 is compared with the numerical predictions.
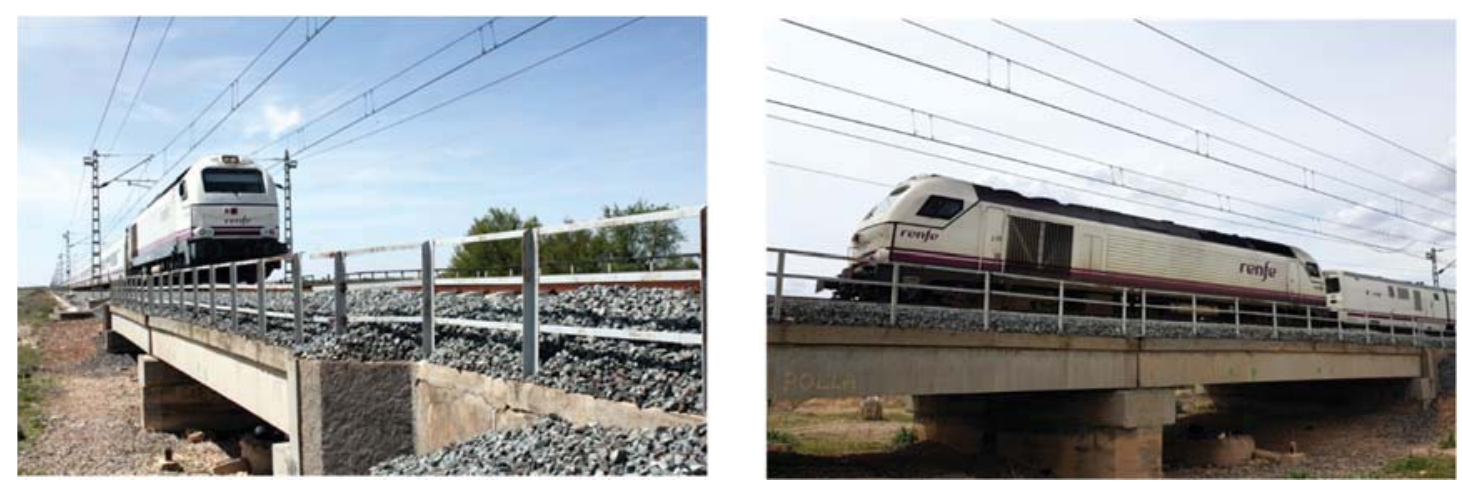

Figure 10: Renfe Altaria Talgo VI trains crossing Old Guadiana Bridge.

It has been verified that the bridge maximum acceleration did not exceed the limit established by the Serviceability Limit State for traffic safety in the case of ballasted tracks [1] according to the measurements in all the sensors.

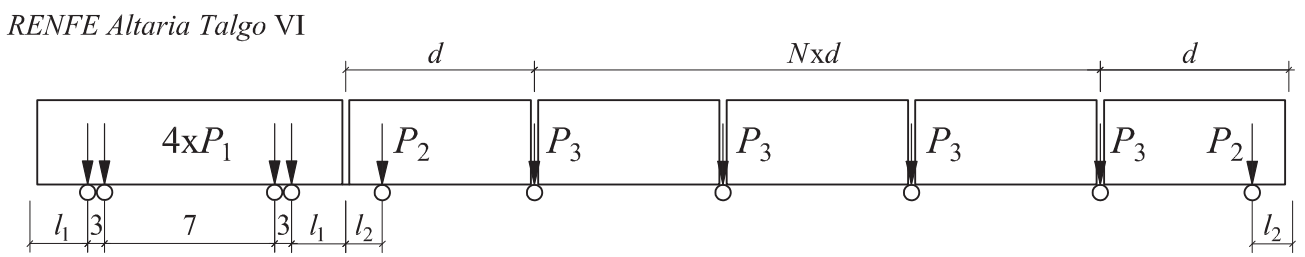

Figure 11: Renfe medium distance Altaria Talgo VI train axle scheme.

\begin{tabular}{lcccccccc}
\hline Train & $N$ & $d(\mathrm{~m})$ & $d_{1}(\mathrm{~m})$ & $l_{1}(\mathrm{~m})$ & $l_{2}(\mathrm{~m})$ & $P_{1}(\mathrm{kN})$ & $P_{2}(\mathrm{kN})$ & $P_{3}(\mathrm{kN})$ \\
\hline Altaria & 7 & 13.14 & -- & 3.44 & 3.3 & 225 & 70 & 140 \\
\hline
\end{tabular}

Table 2: RENFE Altaria Talgo VI features

Fig. 12 shows an experimental vs. numerical comparison of the vertical acceleration at sensors 5 and 6 under the circulation of the northbound train, in the time (a)-(b) and frequency (c)(d) domains. The Talgo passenger coaches present a distance between shared axles of $13.14 \mathrm{~m}$. The theoretical resonant speed associated to this length for the third resonance of the 
fundamental mode is approximately $159 \mathrm{~km} / \mathrm{h}$, which is close to the real speed. This can be detected in the time-history plots where two oscillations of decreasing amplitude take place between the passage of consecutive axles.

$$
V_{1}^{r, j=3}=\frac{d f_{1}}{3} 3.6=158.7 \frac{\mathrm{km}}{\mathrm{h}} \approx 154.8 \frac{\mathrm{km}}{\mathrm{h}}=V
$$
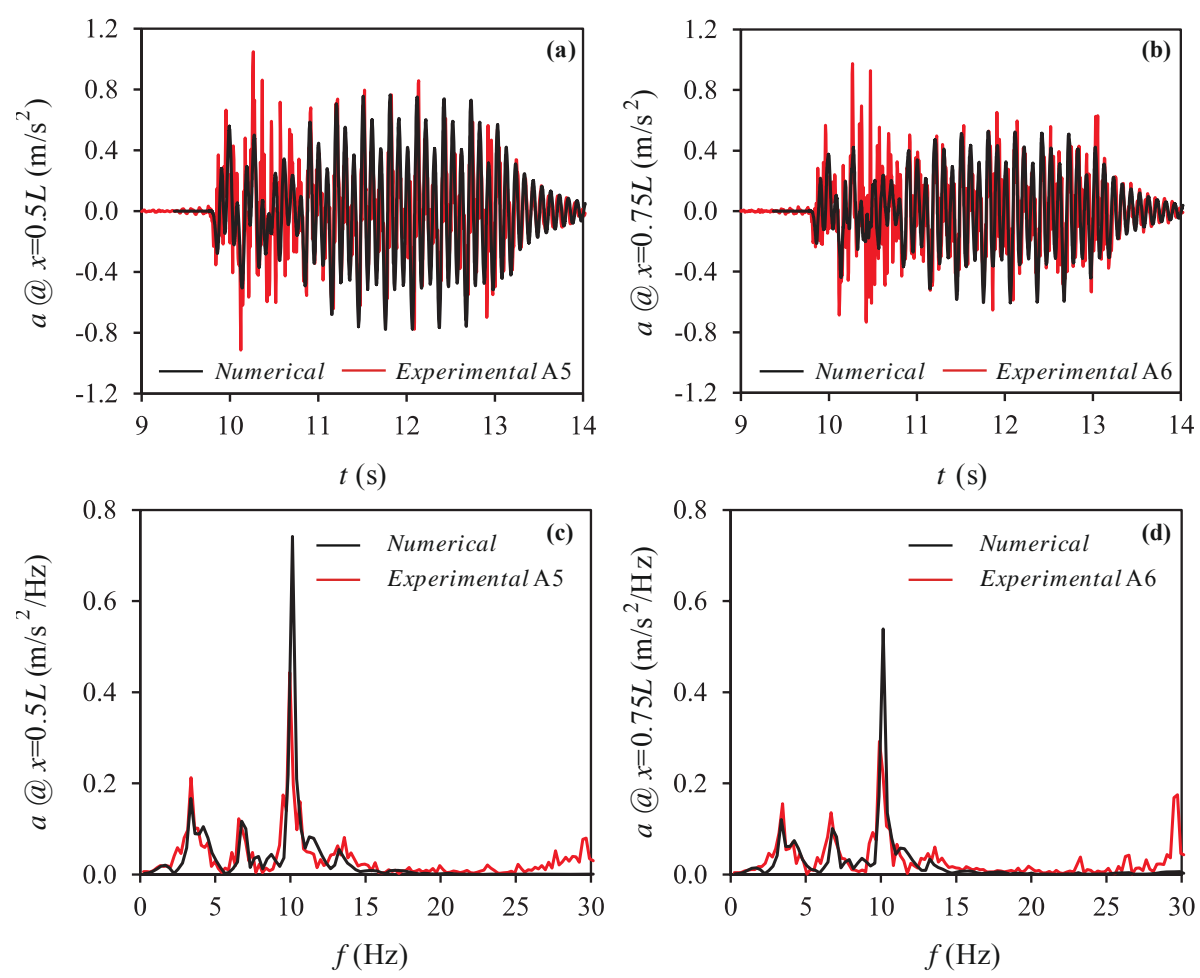

Figure 12: (a)-(b) Time history and (c)-(d) frequency content of the acceleration response at sensors 5 and 6 induced by Altaria Talgo VI train. Numerical prediction (black trace) vs. experimental measurements (red trace). Northbound train (track \#2).

The accuracy of the numerical model is found reasonable up to $30 \mathrm{~Hz}$, both at $L / 2$ and $3 L / 4$ of the first span, although the numerical model overpredicts the acceleration for contributions close to the bridge fundamental frequency. This can be associated to vehicle-structure interaction which is not taken into account and can be of importance, specially at resonance; or to other energy dissipation mechanisms amplitude dependent such as the interaction between the adjacent decks, etc.

Fig. 13 shows the same type of comparative for the southbound train. In this case the acceleration is compared at sensors 13 and 17, located at mid-span of the second and first spans, respectively. Again, the time-history response is well reproduced, especially after the passage of the locomotive. In the frequency domain again, a predominant peak is detected showing the important contribution of the fundamental mode with a certain overprediction of the acceleration in the numerical case.

\subsection{Coupling effect between adjoining decks}

Finally, the coupling effect between the adjacent decks in each span is evaluated in forced vibration. Figs. 14(a)-(c) represent for the northbound train travelling along track $\# 2$ the experimental response measured at sensor 5 (at mid-span under the loaded track) and, simultaneously, at sensor 17 (at mid-span under the adjacent unloaded track). 

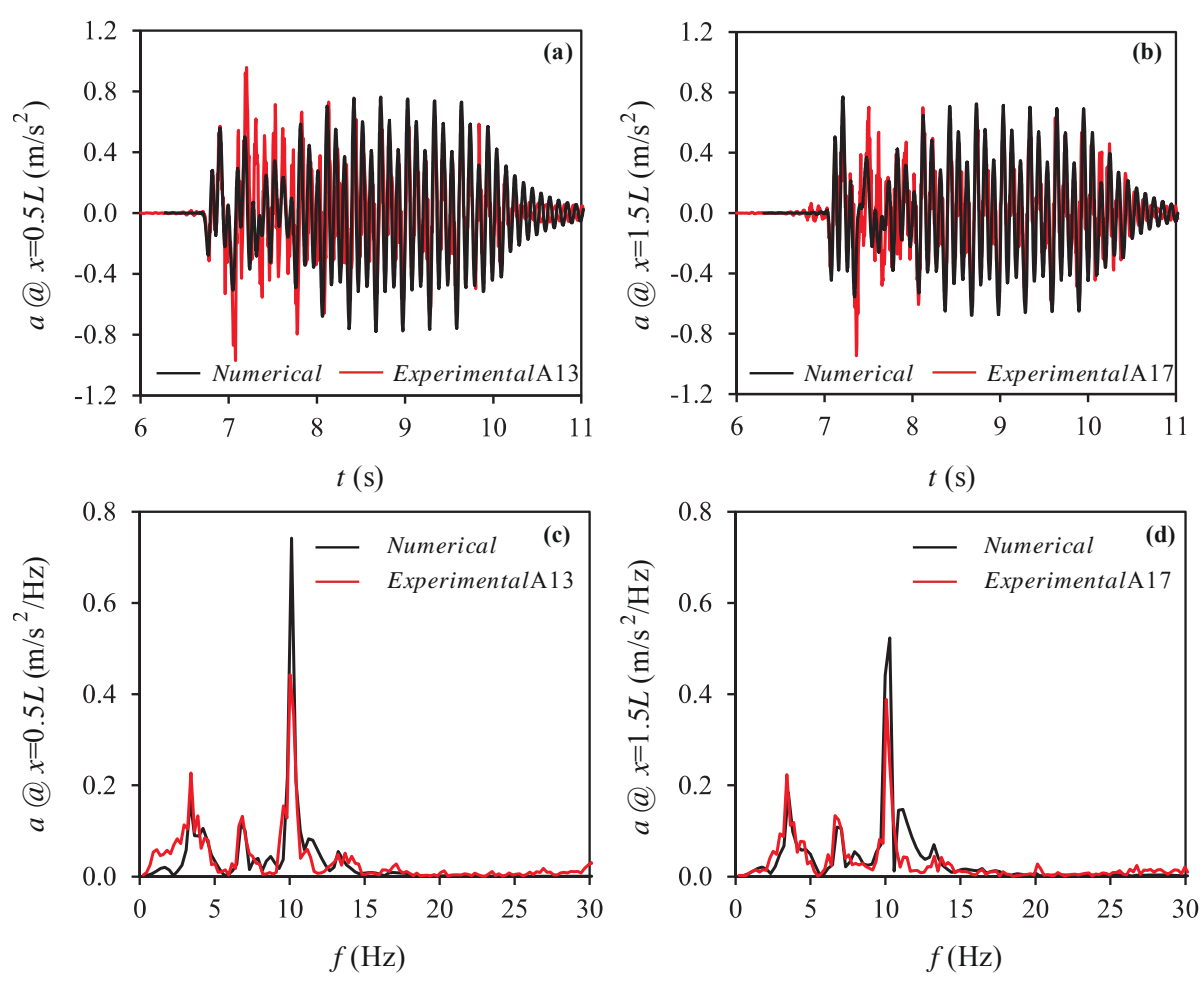

Figure 13: (a)-(b) Time history and (c)-(d) frequency content of the acceleration response at sensors 13 and 17 induced by Altaria Talgo VI train. Numerical prediction (black trace) vs. experimental measurements (red trace). Southbound train (track \#1).
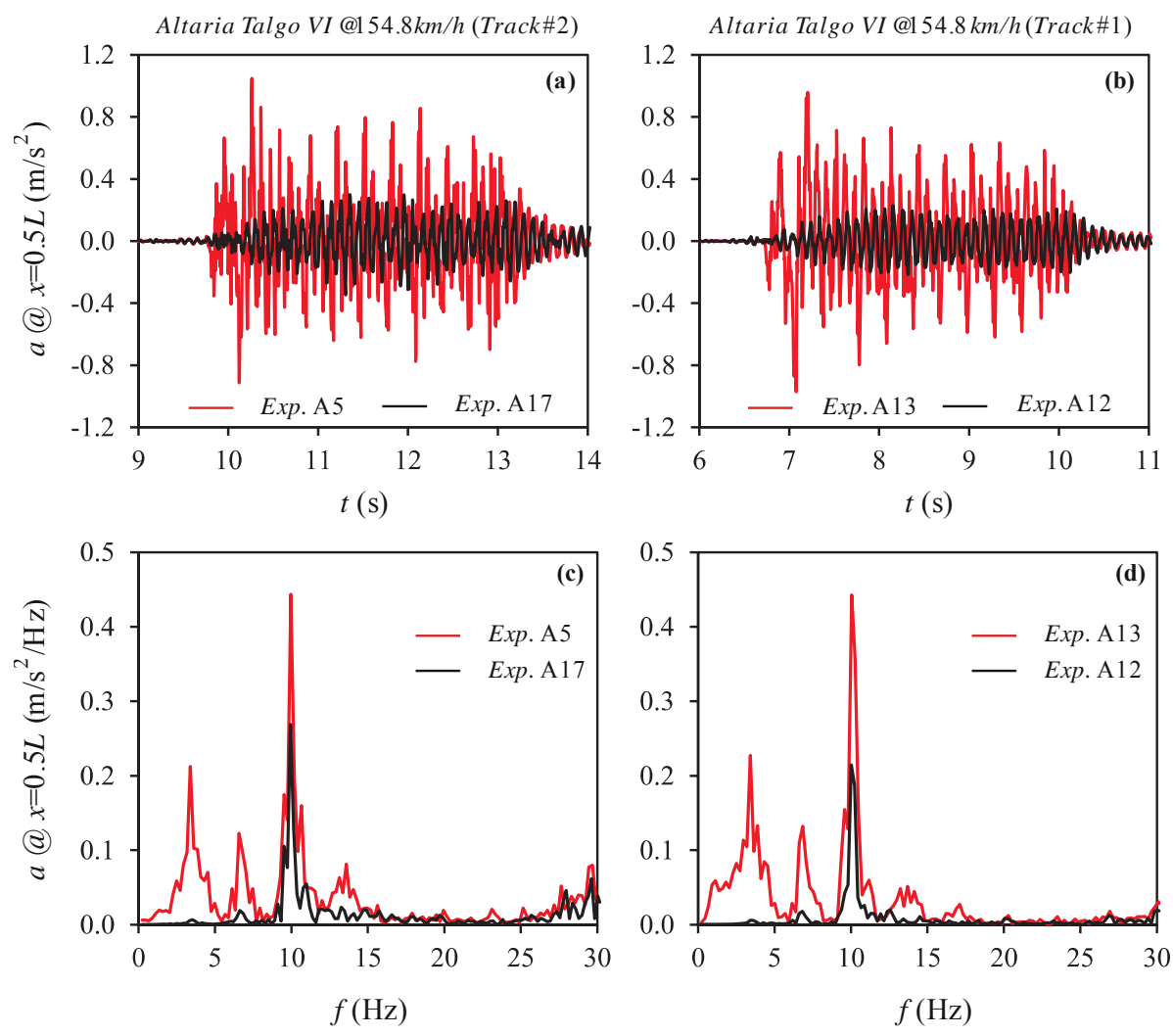

Figure 14: (a)-(b) Time history and (c)-(d) frequency content of the acceleration response at sensors 5 and 17 induced by the northbound train, and at sensors 13 and 12 induced by the southbound train. 
The transmission of vibrations between the two decks is evident, even though these are only connected by the continuous ballast layer. At the unloaded sensor the frequency peaks associated to the excitation (e.g. bogie distance) which are visible in the low frequency range in the loaded sensor, are almost not perceptible; but the acceleration at the fundamental frequency reaches $60.6 \%$ de value in the loaded sensor. The same effect may be observed under the circulation of the southbound train when one compares the response between sensors 13 (under loaded track) and 12 (adjacent deck at symmetrical position). In this case the maximum acceleration in the unloaded sensor at the fundamental frequency in the frequency domain attains $48.5 \%$ the same maximum measured at sensor 13 . This vibration transmission can be caused both by the continuous ballast layer and by the common foundations shared by the decks. In the opinion of the authors this phenomenon deserves further investigation. Implementing a 3D model of the bridge-track system would permit to evaluate the vibration transmitted between the decks close to the shared border in the frequency range of interest.

\section{CONCLUSIONS}

The present article constitutes a preliminary analysis on the longitudinal and transverse coupling effects exerted by the track on simply-supported bridges with independent single-track decks. From this study, the following can be concluded:

- There is a very high dispersion in the track parameters admitted by different authors for similar track infrastructures. The rail pad stiffness seems to affect the most the bridge maximum acceleration specially at high-order resonances, leading to lower amplitudes for higher flexibilities of this parameter. The ballast stiffness affects in a similar way, although to a lower extent. The damping parameters of the track do not seem to affect the bridge maximum response below $60 \mathrm{~Hz}$. These parameters do affect the track response but at much higher frequencies.

- Considering one span in multi-span bridges may not lead to the maximum predicted acceleration when the track is included in the numerical model. The effect of the number of spans gains importance at resonance. The model leading to the maximum dynamic response as well as the most critical section depend on the maximum velocity of interest.

- The experimental vs. numerical predictions in the case of Old Guadiana bridge are reasonable in the sensors located along the longitudinal axis of the decks, as there is no contribution of the torsion mode at those locations. The numerical model tends to overestimate the real response close to the bridge natural frequency.

- The transmission of vibrations from the loaded deck to the unloaded deck is relevant. This may be caused by the continuous ballast layer but also by the shared foundations of the two decks. In the authors' opinion this effect is not well known and should be investigated using a 3D model of the complete bridge.

\section{ACKNOWLEDGEMENTS}

The authors would like to acknowledge the financial support provided by (i) Generalitat Valenciana under AICO/2019/175 research project, (ii) the Spanish Ministry of Economy and Competitiveness under research project [BIA2016-75042-C2], and Universitat Jaume I annual research plan under action [UJI/A2018/06]. 


\section{REFERENCES}

[1] CEN EN-1990, Eurocode: Basis of structural design. Annex 2: Application for bridges, (2002).

[2] ERRI D214: Rail bridges for speeds $>200 \mathrm{~km} / \mathrm{h}$. final report. Part a. Synthesis of the results of d 214 research. European Rail Research Institute (1999).

[3] W. Hoorpah, Dynamic calculations of high-speed railway bridges in France -some case studies, Dynamics of High-Speed railway bridges, Taylor \& Francis, 2008.

[4] M. Zacher, M. Baeßler, Dynamic behaviour of ballast on railway bridges, Dynamics of High-Speed Railway Bridges, Taylor \& Francis, 2008.

[5] W. Zhai, Z. Han, Z. Chen, L. Ling, S. Zhu, Train-track-bridge dynamic interaction: a state-of-the-art review, Vehicle System Dynamics 7, 984-1027, 2019.

[6] C. Rigueiro, C. Rebelo, L. Simões da Silva, Influence of ballast models in the dynamic response of railway viaducts, Journal of Sound and Vibration 329, 3030-3040, 2010.

[7] K. Liu, G. Lombaert, G. De Roeck, Dynamic analysis of multispan viaducts with weak coupling between adjacent spans, Journal of Bridge Engineering 19(1), 83-90, 2014.

[8] C. Rebelo, L. Simões da Silva, C. Rigueiro, M. Pircher, Dynamic behaviour of twin single-span ballasted railway viaducts. Field measurements and modal identification, Engineering Structures 30, 2460-2469, 2008.

[9] W. Zhai, K. Wang, J. Lin, Modelling and experiment of railway ballast vibrations, Journal of Sound and Vibration 270, 673-683, 2004.

[10] G. Kouroussis, D.P. Connolly, G. Alexandrou, K. Vogiatzis, The effect of railway local irregularities on ground vibration. Transportation Research Part D 39, 17-30, 2015.

[11] Y.Q. Sun, M. Dhanasekar, Influence of the railway track parameters to the vertical and lateral impact, Conference on Railway Engineering, Wollongong, 2002.

[12] A.H. Jesús, Z. Dimitrovová, M.A.G. Silva, A statistical analysis of the dynamic response of a railway viaduct, Engineering Structures 71, 244-259, 2014.

[13] M. Naemi, J.A. Zakeri, M. Esmaeili, M. Mehrali, Dynamic response of sleepers in a track with uneven rail irregularities using a 3D vehicle-track model with sleeper beams, Archives of Applied Mechanics 85,1679-1699, 2015.

[14] G. Lombaert, G. Degrande, J. Kogut, S. François, The experimental validation of a numerical model for the prediction of railway induced vibrations, Journal of Sound and Vibration 297, 512-535, 2006.

[15] G. Kouroussis, G. Gazetas, I. Anastasopoulos, C. Conti, O. Verlinden, Discrete modelling of vertical track-soil coupling for vehicle-track dynamics, Soil Dynamics and Earthquake Engineering 31, 1711-1723, 2011.

[16] C. Esveld, Modern railway track, Delft University of Technology, 2001.

[17] K. Nguyen, J.M. Goicolea, F. Gabaldón, Comparison of dynamic effects of high-speed traffic load on ballasted track using a simplified two-dimensional and full three-dimensional model, Journal of Rail and Rapid Transit 228(2), 128-142, 2012. 
[18] W.M. Zhai, Two simple fast integration methods for large-scale dynamic problems in engineering, International Journal for Numerical Methods in Engineering 39, 4199-4214, 1996.

[19] E. Bongini, F. Poisson, Ground vibrations simulation cases parameters, Technical report, SNCF, France, 2009.

[20] Z. Chen, W. Zhai, K. Wang, A locomotive-track coupled vertical dynamics model with gear transmissions, Vehicle System Dynamics 55(2), 244-267, 2017.

[21] P. Lou, A vehicle-track-bridge interaction element considering vehicle's pitching effect, Finite Elements in Analysis and Design 41, 397-427, 2005.

[22] R.A. Clark, P.A. Dean, J.A. Elkins, S.G. Newton, An investigation into the dynamic effects of railway vehicles running on corrugated rails, Journal of Mechanical Engineering Science 24(2), 65-76, 1982.

[23] M.D. Martínez-Rodrigo, J. Lavado, P. Museros, Dynamic performance of existing highspeed railway bridges under resonant conditions retrofitted with fluid viscous dampers, Engineering Structures 32, 808-828, 2010.

[24] CEN EN-1991-2, Eurocode 1. Actions on structures. Part 2: Traffic loads on bridges, 2003. 